\title{
Biological, biochemical and molecular features of Trypanosoma cruzi strains isolated from patients infected through oral transmission during a 2005 outbreak in the state of Santa Catarina, Brazil: its correspondence with the new T. cruzi Taxonomy Consensus (2009)
}

\author{
Sonia Gumes Andrade ${ }^{1 /+}$, Rozália Figueira Campos ${ }^{1,2}$, Mario Steindel ${ }^{3}$, \\ Marcos Lázaro Guerreiro', Juracy Barbosa Magalhães ${ }^{1,+}$, Marcio Cerqueira de Almeida', \\ Joice Neves Reis ${ }^{4}$, Viviane Corrêa Santos ${ }^{5}$, Helder Magno Silva Valadares ${ }^{5,7}$, \\ Mitermayer Galvão dos Reis ${ }^{6}$, Andréa Mara Macedo ${ }^{5}$
}

\author{
'Laboratório de Chagas Experimental, Autoimunidade e Imunologia Celular ${ }^{4}$ Laboratório de Epidemiologia Molecular \\ ${ }^{6}$ Laboratório de Patologia Celular e Molecular, Centro de Pesquisas Gonçalo Moniz-Fiocruz, Salvador, BA, Brasil \\ ${ }^{2}$ Universidade Estadual de Feira de Santana, Feira de Santana, BA, Brasil ${ }^{3}$ Departamento de Microbiologia e Parasitologia, \\ Universidade Federal de Santa Catarina, Florianópolis, SC, Brasil ${ }^{5}$ Departamento de Bioquímica e Imunologia, \\ Universidade Federal de Minas Gerais, Belo Horizonte, MG, Brasil ``Universidade Federal de São João Del-Rey, Divinópolis, MG, Brasil
}

We examined strains of Trypanosoma cruzi isolated from patients with acute Chagas disease that had been acquired by oral transmission in the state of Santa Catarina, Brazil (2005) and two isolates that had been obtained from a marsupial (Didelphis aurita) and a vector (Triatoma tibiamaculata). These strains were characterised through their biological behaviour and isoenzymic profiles and genotyped according to the new Taxonomy Consensus (2009) based on the discrete typing unities, that is, T. cruzi genotypes I-VI. All strains exhibited the biological behaviour of biodeme type II. In six isolates, late peaks of parasitaemia, beyond the 20th day, suggested a double infection with biodemes II + III. Isoenzymes revealed Z2 or mixed Z1 and Z2 profiles. Genotyping was performed using three polymorphic genes (cytochrome oxidase II, spliced leader intergenic region and $24 S \alpha$ rRNA) and the restriction fragment length polymorphism of the kDNA minicircles. Based on these markers, all but four isolates were characterised as $\mathrm{T}$. cruzi II genotypes. Four mixed populations were identified: SC90, SC93 and SC97 (T. cruzi I + T. cruzi II) and SC95 (T. cruzi I + T. cruzi VI). Comparison of the results obtained by different methods was essential for the correct identification of the mixed populations and major lineages involved indicating that characterisation by different methods can provide new insights into the relationship between phenotypic and genotypic aspects of parasite behaviour.

Key words: Trypanosoma cruzi strains - oral transmission - biodemes - genotyping - Taxonomy Consensus 2009

Outbreaks of acute Chagas disease related to the accidental ingestion of food contaminated with Trypanosoma cruzi have been registered in several Brazilian regions, such as in Teutônia, Rio Grande do Sul, (Nery-Guimarães et al. 1968, Neves da Silva 1968), Catolé do Rocha, Paraíba (Shikanai-Yasuda et al. 1991) and the Brazilian Amazon (Valente et al. 1999, 2009, Pinto et al. 2001).

In 2005, in the Brazilian state of Santa Catarina (SC), an outbreak of acute Chagas disease was associated with the ingestion of sugar cane juice, which was likely contaminated with $T$. cruzi by a naturally infected insect vector during its preparation (Steindel et al. 2008). All the infected people had acquired the infection at the same municipality of Navegantes and the commonality between

Financial support: FAPESB (to SGA), FAPEMIG, CNPq, CAPES (to AMM)

† In memoriam

+ Corresponding author: sgandrade@bahia.fiocruz.br

Received 25 April 2011

Accepted 22 September 2011 individuals was the ingestion of sugar cane juice at the same time and place. Twenty-four people were infected and developed acute Chagas disease, three cases of which were fatal. A total of nine T. cruzi strains were isolated through haemoculture from the infected individuals by $\mathrm{Dr}$ Mario Steindel [Microbiology and Parasitology Division, Federal University of Santa Catarina (UFSC), Florianópolis, SC] who had also isolated T. cruzi from one Triatoma tibiamaculata collected in the neighbourhood and from marsupials (Didelphis aurita and Didelphis marsupialis) captured in the same area. A molecular and isoenzymic study of the isolated strains was initially performed by Steindel et al. (2008). These authors detected the presence of T. cruzi II (Anonymous 1999) in the human isolates, double infection with T. cruzi I and T. cruzi II in the triatomine and T. cruzi I in the marsupials.

Our laboratory (Gonçalo Moniz Research CentreFiocruz, state of Bahia) received the isolated strains in liver infusion tryptose (LIT) culture media from Dr Mario Steindel in 2006. All the isolates were submitted to biological characterisation by inoculation into mice to evaluate their behaviour in an experimental vertebrate host and to determine their isoenzymic patterns (Miles et al. 1980, Andrade et al. 1983, Andrade \& Magalhães 
1997). The studies revealed that all the samples exhibited the biological patterns of biodeme type II (Andrade et al. 2006b) presumably corresponding to T. cruzi II major lineages (Anonymous 1999).

In 2009, during a commemorative event for the centenary of the discovery of Chagas disease, a new consensus for T. cruzi subdivision into major groups was established. Six discrete typing units (DTUs) (Tibayrenc 1998, 2003, Brisse et al. 2000) were formally recognised and characterised as the genotypes $T$. cruzi I through $T$. cruzi VI (Zingales et al. 2009). The epidemiological relevance of the six DTUs is not completely established, but at least four of the genotypes (T. cruzi I, II, V and VI) appear to be primarily involved with human disease. T. cruzi III and IV are rarely isolated from humans, but these genotypes, along with $T$. cruzi I, have been implicated in outbreaks of orally transmitted, acute cases of Chagas disease, especially in the Amazon Basin (Valente et al. 2009).

The present report is an attempt to compare the results obtained from the former characterisation of the strains isolated from the outbreak of Chagas disease due to oral infection in 2005 (Andrade et al. 2006b) to a new set of recently obtained data, using biological (biodemes) (Andrade 1974, 1985, Andrade \& Magalhães 1997), biochemical (zymodemes) (Miles et al. 1980, Andrade et al. 1983) and molecular approaches. The molecular approaches were targeted to both the kinetoplast [maxicircle and minicircle restriction fragment length polymorphism (RFLP) analyses] and nuclear [internal transcribed spacer (ITS) spliceleader and 24S $\alpha$ rRNA gene analyses] genomes. The main goal of this broad study was not only to determine the major genotypes of the strains in accordance with the new classification (Zingales et al. 2009) but also to characterise the molecular variability of the samples, identifying polyclonal or mixed populations and correlating the findings to the biological behaviour of the strains.

\section{SUBJECTS, MATERIALS AND METHODS}

Biodemes characterisation - T. cruzi strains - A total of 11 strains were studied as follows: nine strains (SC94, SC95, SC96, SC97, SC98, SC99, SC100, SC101, SC102) isolated by haemoculture from acute human cases of Chagas disease acquired by oral transmission after the ingestion of a contaminated sugar cane juice in Navegantes (Steindel et al. 2008), one strain (SC90) isolated from an oposum (Didelphis aurita) and one strain (SC93) from a triatomine (T. tibiamaculata), both from the same area as the disease outbreak. The cultures were received from the Protozoology Laboratory of UFSC and kindly provided by Dr Mario Steindel.

Inoculation in mice - The culture forms in LIT medium were submitted to three successive washing in phosphate buffered saline (PBS), $\mathrm{pH} 7.2$, under centrifugation at $750 \mathrm{~g}$. After resuspension in PBS, $\mathrm{pH}$ 7.2, the pellet was examined in a Neubauer chamber and the number of metacyclic forms in $1 \mu \mathrm{L}$ was evaluated. For mice in the first passage group, $10^{4}-20^{4}$ metacyclic forms were used as the inocula.

Experimental groups - For each strain, blood forms obtained from the first passage group were intraperitoneally inoculated into 60 Swiss mice weighing 15-20 g.
The behaviour of parasites was evaluated in the second and fifth passages in mice. Inoculum: $5 \times 10^{4}$ blood trypomastigotes.

Parasitaemia - Parasitaemia was evaluated daily in a sample of five mice per experimental group by counting the number of trypomastigotes in $5 \mu \mathrm{L}$ of peripheral blood in 50 microscopic fields (400X).

Cumulative mortality - The cumulative mortality was registered and expressed as the percentage of dead animals for each group until 30 days after the initial infection, excluding those killed for the histopathological study.

Histopathology - Three mice were killed at the following time points: the seventh, 10th, 14th, 20th and 30 th days after infection. Tissue sections of the heart, skeletal muscles, liver and spleen were fixed in $10 \%$ formalin and embedded in paraffin and $5-\mu \mathrm{m}$ sections were stained with haematoxylin-eosin.

Isoenzymic characterisation - The strains were cultivated into Warren medium and the isoenzymic extracts were obtained according to Miles et al. (1980). The enzymes that distinguish biodemes types I, II and III (Andrade et al. 1983) were used as follows: aspartate amino transferase (ASAT), alanino aminotransferase (ALAT), phosphoglucomutase (PGM) and glucosephosphate isomerase (GPI). Thin-layer starch-gel electrophoresis was performed by application of $30 \mathrm{~V} / \mathrm{cm}$ for $90 \mathrm{~min}$ for ALAT and for $60 \mathrm{~min}$ for ASAT and $20 \mathrm{~V} / \mathrm{cm}$ for $150 \mathrm{~min}$ for GPI and for 120 min for PGM. The enzymes ALAT and ASAT were developed with 0.1 M PBS and BNAD and examined by ultraviolet light. For the enzymes GPI and PGM, 0.3 M TRIS/HCl buffer and nicotinamide adenine dinucleotide phosphate were used in addition to $0.36 \mathrm{mM}$ MTT (dimethilthiazole 2- $\gamma 12$-5 diphenil tetrazolium bromide), $10.06 \%$ agar gel and $0.03 \mathrm{mM}$ phenazine metasulfate. As a control for isoenzyme characterisation, the prototypes of each of the three biodeme types were included in each electrophoretic run: Peruvian (type I), 12SF (type II) and Colombian (type III).

Molecular characterisation of the kinetoplast genome - RFLP of kDNA minicircle variable regions: schizodemes were performed according to Avila et al. (1990), using the previously described oligonucleotide primers S35 and S36 to amplify fragments of $330 \mathrm{bp}$. Each polymerase chain reaction (PCR) round had two negative controls (ultra-pure water and normal serum from a human patient). Following the PCR, the minicircle amplicons were digested with RsaI, Hinf I and EcoRI restriction endonucleases, electrophoresed in a $7 \%$ polyacrylamide gel and visualised using the system Eagle Eye I after ethidium bromide staining. Well-defined and reproducible bands identified in the electrophoretic profiles were scored for the presence or absence of characteristics in each tested T. cruzi isolate.

RFLP of the mitochondrial cytochrome oxidase (CO) 2 gene - Amplification of the mitochondrial $\mathrm{CO}$ subunit 2 (COII) gene was performed with the primers Tcmit10 (5'-CCATATATTGTTGCATTATT-3') and Tcmit21 (5'-TTGTAATAGGAGTCATGTTT-3'), which were 
designed to amplify a fragment of $375 \mathrm{bp}$ from $T$. cruzi maxicircle DNA, as described by Freitas et al. (2006). Following PCR, the COII amplicons were digested with the $A l u \mathrm{I}$ restriction enzyme and the fragments were analysed on a silver-stained $6 \%$ polyacrylamide gel, which enabled the differentiation of T. cruzi I, II and III-VI genotypes. For RFLP-COII standards, we used DNA obtained from strains or clones that exhibited mitochondrial haplotype A, corresponding to T. cruzi I (Col 17G2: fragments of 30 , 81 and $264 \mathrm{bp}$ ), haplotype $\mathrm{C}$, corresponding to $T$. cruzi II (JG: fragments of 81, 82 and $212 \mathrm{bp}$ ) and haplotype B (CL Brener: fragments of 81 and $294 \mathrm{bp}$ ). The B haplotype is associated with $T$. cruzi III, IV, V and VI genotypes.

Molecular characterisation of the nuclear genome - Molecular typing of the intergenic regions of the T. cruzi mini-exon gene - The molecular typing of the ITS of the splice-leader was performed in accordance to Burgos et al. (2007) using the primers TcIII (5'-CTCCCCAGTGTGGCCTGGG-3') and UTCC (5'-CGTACCAATATAGTACAGAAACTG-3'). This PCR strategy, which targets the spliced leader intergenic region (SLIR) gene, was devised to distinguish populations belonging to T. cruzi III and IV (amplicons of $\sim 200 \mathrm{bp}$ ) from T. cruzi I, II, V and VI, which present fragments of $\sim 150 \mathrm{bp}$ (Burgos et al. 2007). The PCR products were analysed by electrophoresis in $2 \%$ agarose gels stained with ethidium bromide. As reference amplicons for the SL-IR genes, we used DNA obtained from strains and clones that present fragments of $\sim 200 \mathrm{bp}$ (231, T. cruzi III) and $\sim 150$ bp (CL Brener, T. cruzi VI).

Amplification of the D7 domain of the 24S $\mathrm{rRNA}$ The 24S $\alpha$ rRNA analysis was conducted according to Souto et al. (1996) using the primers D71 (5'-fluorescein-AAGGTGCGTCGACAGTGTGG-3') and D72 (5'-
TTTTCAGAATGGCCGAACAGT-3'). As PCR amplification controls for this gene, we used DNA from JG (a fragment of $125 \mathrm{bp}$, rDNA type 1), Col 17G2 (a fragment of $110 \mathrm{bp}$, rDNA type 2) and $\mathrm{SO} 3 \mathrm{cl} 5$ (fragments of 110 and $125 \mathrm{bp}$, rDNA type 1/2). The PCR products were analysed by electrophoresis in silver-stained $6 \%$ polyacrylamide gels or, to better determinate the allele sizes, fluorescent products were analysed on a $6 \%$ denaturing polyacrylamide gel of an automatic laser fluorescent sequencer (GE Healthcare, Milwaukee, Wisconsin, USA) and compared with the fluorescent DNA fragments of 50-500 bp using the Allelelocator software (GE Healthcare).

\section{RESULTS}

Biological characterisation (biodemes) - Inoculation of each strain into Swiss outbreed mice determined the patent infection of the experimental animals. Strain characterisation was based on the following parameters: evolution of parasitaemia, virulence, mortality rate and pathogenicity for mice, histopathological lesions and tissue tropism. The evaluation of these parameters identified a predominant pattern of biodeme type II (Table I).

Parasitaemia - Parasitaemia was evaluated in the experimental groups in the second or fifth passages into mice. Parasitemic curves are shown in Fig. 1A-D. Strains isolated either from a marsupial or a triatomine (SC90 and SC93), as well as the strains SC94, SC95, SC100, which were isolated from human patients, showed irregular peaks from the 12th to the 20th day, characteristic of biodeme type II. Strain SC94 was the most virulent, with the earliest parasitemic peak. Strains SC96, SC97, SC98, SC99, SC101 and SC102, isolated from six of the infected humans, exhibited an early and low parasitemic peak from the 12th to the 20th day and a late peak after the 20th day, which are characteristic of biodeme type III.

TABLE I

Biodemes and zymodemes: strains from oral transmission outbreak in the state of Santa Catarina, Brazil, 2005

\begin{tabular}{|c|c|c|c|c|c|c|}
\hline \multirow{3}{*}{$\begin{array}{l}\text { Identification } \\
\text { Strains } \\
\text { SC90 }\end{array}$} & \multicolumn{2}{|c|}{$\begin{array}{c}\text { Biodemes } \\
\text { (passages into mice) }\end{array}$} & \multicolumn{4}{|c|}{$\begin{array}{l}\text { Zymodemes } \\
\text { (culture forms) }\end{array}$} \\
\hline & Origin & Biodeme types & PGM & GPI & ASAT & ALAT \\
\hline & Didelphis aurita & II & $\mathrm{Z1}$ & $\mathrm{Z} 1 / \mathrm{Z} 2$ & $\mathrm{Z1}$ & $\mathrm{Z1}$ \\
\hline SC93 & Triatoma tibiamaculata & $\mathrm{II}^{a}$ & $\mathrm{Z1}$ & $\mathrm{Z} 2$ & $\mathrm{Z1}$ & $\mathrm{Z} 2$ \\
\hline SC94 & Human & II & $\mathrm{Z} 2$ & $\mathrm{Z} 2$ & ND & $\mathrm{Z} 2$ \\
\hline SC95 & Human & II & $\mathrm{Z1}$ & $\mathrm{Z} 2$ & ND & ND \\
\hline SC96 & Human & $\mathrm{II}^{a}$ & $\mathrm{Z} 2$ & $\mathrm{Z} 2$ & $\mathrm{Z} 2$ & $\mathrm{Z1}$ \\
\hline SC97 & Human & $\mathrm{II}^{a}$ & $\mathrm{Z1}$ & $\mathrm{Z} 2$ & $\mathrm{Z1}$ & $\mathrm{Z1}$ \\
\hline SC98 & Human & $\mathrm{II}^{a}$ & $\mathrm{Z} 2$ & $\mathrm{Z} 2$ & $\mathrm{Z1}$ & $\mathrm{Z1}$ \\
\hline SC99 & Human & $\mathrm{II}^{a}$ & $\mathrm{Z1}$ & $\mathrm{Z} 2$ & $\mathrm{Z} 2$ & $\mathrm{Z1}$ \\
\hline SC100 & Human & II & $\mathrm{Z} 2$ & $\mathrm{Z} 2$ & ND & $\mathrm{Z1}$ \\
\hline SC101 & Human & $\mathrm{II}^{a}$ & $\mathrm{Z} 2$ & $\mathrm{Z} 2$ & $\mathrm{Z} 2$ & $\mathrm{Z1}$ \\
\hline SC102 & Human & II & $\mathrm{Z} 2$ & $\mathrm{Z} 2$ & $\mathrm{Z2}$ & $\mathrm{Z1}$ \\
\hline
\end{tabular}

$a$ : strains that showed an early and a late peak of parasitaemia, suggesting double infection with biodemes II and III; ALAT: alanino aminotransferase; ASAT: aspartate amino transferase; GPI: glucosephosphate isomerase; ND: not determined; PGM: phosphoglucomutasa. 
Mortality - Table II shows the cumulative mortality rates until the 30th day post-infection for the mice infected with each strain. The percentage mortality for the mice infected with the strains SC90, SC93, SC95 and SC98 was zero. Strains SC96, SC97, SC100, SC101 and $\mathrm{SC} 102$ caused $50 \%$ mortality of the infected mice; strains SC94 and SC99 caused 100\% mortality.

Virulence - Based on the mortality rate at 30 days, as shown in Table II, and the parasitaemia and the severity of tissue lesions, the strains were classified as "low virulence", corresponding to $0 \%$ mortality, "medium virulence", corresponding to $50 \%$ mortality and "high virulence", corresponding to $100 \%$ mortality. The strains SC94 and SC99 exhibited high virulence and produced intense cardiac lesions in mice.

Isoenzymes patterns - Table I shows the results of the isozymic profiles for PGM, GPI, ASAT and ALAT analysis of the strains. The strain SC90, from D. aurita, exhibited the profile of zymodeme Z1 in PGM, ASAT and ALAT analyses and a mixed profile Z1/Z2 in GPI analysis; strain SC93, from T. tibiamaculata, exhibited a zymodeme Z2 profile when analysed by the enzymes GPI and ALAT and a Z1 profile when analysed by PGM and ASAT. The nine strains isolated from humans (SC94-SC102) exhibited a Z2 profile in eight of the referred strains when analysed by the GPI isoenzyme (SC100 was not performed) and in six of these strains when analysed by PGM.

Histopathological evaluation - Pathogenicity in mice was evaluated by the intensity of the necrotic and inflammatory lesions in the heart and skeletal muscles (Figs 2, 3). Strains with parasitemic peaks between 12-20 days post-infection (SC90, SC94 and SC100) exhibited histopathological lesions characteristics of biodeme type II, showing mild myocarditis from the seventh to 10th day of infection with diffuse mononuclear infiltrations and presence of $T$. cruzi amastigotes into the cardiac myocells. The inflammatory lesions and cardiac parasitism increased until the 20th day post-infection. The strain SC94, which exhibited high virulence (Table II), pre-
A
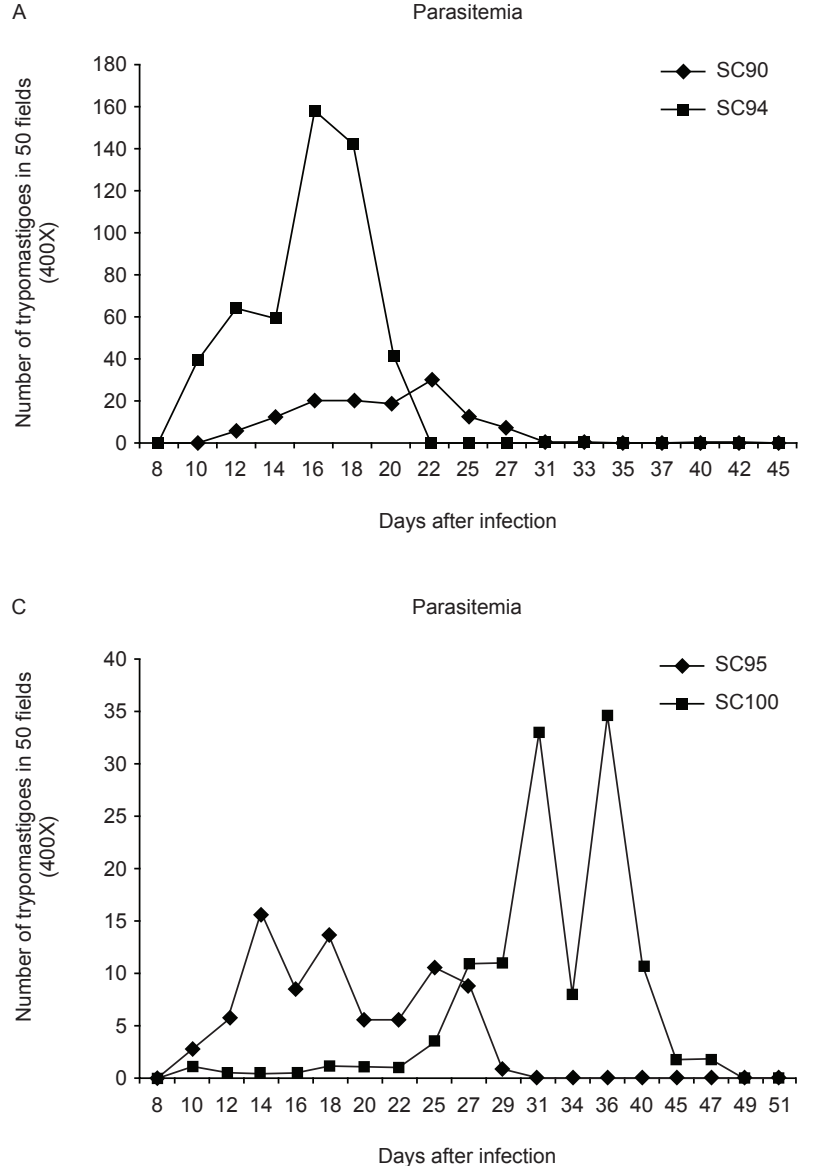

B

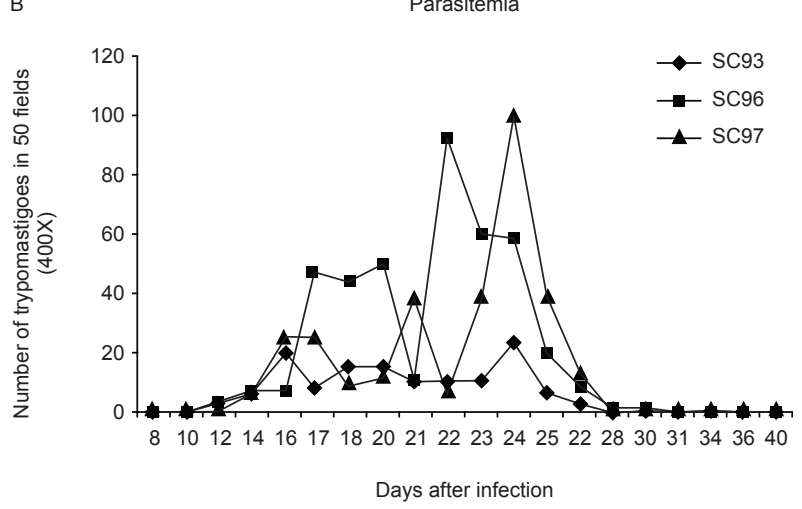

D

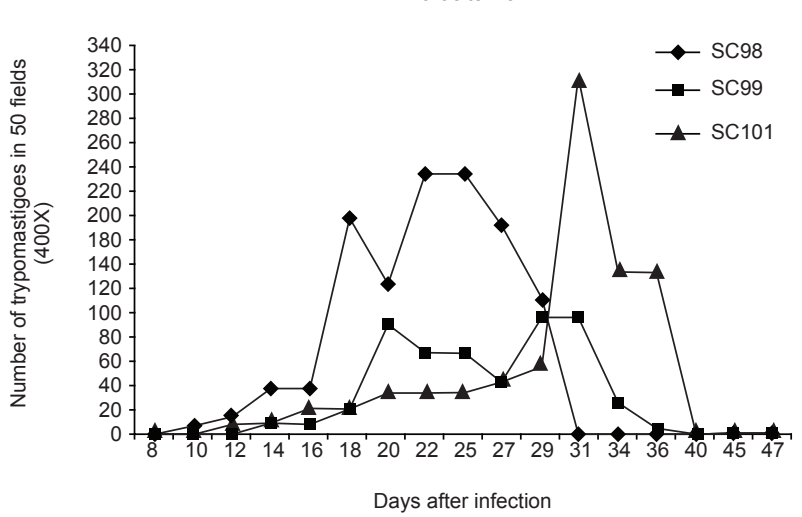

Fig. 1: parasitemic curves of the several strains, disclosed the profiles of the biodemes types (I, II, III) and in some cases the combination of the types II and III. A: strain SC90 showed the parasitemic pattern of the biodeme type II of low virulence. SC94 showed an early high peak corresponding to biodeme type II of high virulence; B: strain SC93 shows the pattern of biodeme type II and the strains SC96 and SC97 a double parasitemic pattern of biodemes types II and III; C: strains SC95 and SC100 show an early parasitemic peak corresponding to biodeme type II and a late peak of the biodeme type III strains; D: strains SC98, SC99 and SC101 show the early peak characteristic of biodeme type II strains and a late peak characteristic of biodeme type III. 
sented with early inflammatory infiltrations in the myocardium and skeletal muscle from the seventh to the 10th day post-infection, with variable evolution to intense cardiac lesions and intense parasitism of cardiac cells from the 14th to the 20th day (Fig. 2A, B). The strains that presented double peaks of parasitaemia (SC96, SC97, SC98, SC99, SC101 and SC102) presented histopathological lesions and intracellular parasitism that were more prominent from the 20th to 30 th days post-infection, with intense inflammatory lesions in the myocardium (Fig. 3A-D) and skeletal muscles (Fig. 3E, F).

Molecular analysis - Typical results from the molecular characterisation of the 11 isolates can be found in Figs 4-7. Compiled molecular data are presented in Table III.

RFLP-COII profiles - Analysis of RFLP-COII profiles for $T$. cruzi populations showed the presence of all three possible haplotypes (Fig. 4). The isolates SC94, SC96, SC98, SC99, SC100, SC101 and SC102 presented the haplotype $\mathrm{C}$ (fragments of 212, 81 and $82 \mathrm{bp}$ ) characteristic of T. cruzi II. The isolates SC90, SC93 and SC97 showed both A and C haplotypes (fragments of 264, 212, $81 / 82$ and $30 \mathrm{bp}$ ), corresponding to a mixture of populations belonging to T. cruzi I and II. The SC95 isolate presented both C and B haplotypes (fragments of 294, 212 and 81/82 bp), corresponding to a mixture of populations belonging to T. cruzi II and one of T. cruzi III, IV, $\mathrm{V}$ or VI (Table III).

Molecular typing of the intergenic regions of T. cruzi spliced leader genes - The analysis of the polymorphism of the ITS region of the spliced leader genes was performed according to Burgos et al. (2007). Using this strategy, all T. cruzi populations presented PCR amplification products of $\sim 150 \mathrm{bp}$, characteristic of $T$. cruzi I, II, $\mathrm{V}$ or VI (Fig. 5) (Table III).

Analysis of the 24S $\alpha$ rRNA gene - The 24S $\alpha$ DNA analysis revealed that the isolates SC94, SC95, SC96, SC98, SC99, SC100, SC101 and SC102 displayed amplicons of $125 \mathrm{bp}$, characteristic of T. cruzi II, IV or VI (Figs 6, 7). Therefore, based on all the molecular data, we concluded that the isolate SC-95 consisted of a mixture of populations belonging to T. cruzi II and VI genotypes, as the ITS analysis rules out the possibility of a

\section{TABLE II}

Cumulative mortality rates of mice/virulence of strains

\begin{tabular}{|c|c|c|}
\hline $\begin{array}{l}\text { Low virulence } \\
\text { ( } 0 \% \text { mortality) }\end{array}$ & $\begin{array}{l}\text { Medium virulence } \\
\text { (until 50\% mortality) }\end{array}$ & $\begin{array}{l}\text { High virulence } \\
\text { (100\% mortality) }\end{array}$ \\
\hline $\mathrm{SC} 90^{a}$ & $\mathrm{SC} 96^{c}$ & $\mathrm{SC} 94^{c}$ \\
\hline $\mathrm{SC} 3^{b}$ & $\mathrm{SC} 97^{c}$ & $\mathrm{SC}^{\circ}{ }^{c}$ \\
\hline $\mathrm{SC}^{\circ}{ }^{c}$ & $\mathrm{SC} 100^{c}$ & - \\
\hline \multirow[t]{2}{*}{$\mathrm{SC} 98^{c}$} & $\mathrm{SC} 101^{c}$ & - \\
\hline & $\mathrm{SC} 102^{c}$ & - \\
\hline
\end{tabular}

$a$ : isolated from Didelphis aurita; $b$ : isolated from Triatoma tibiamaculata; $c$ : isolated from humans. mixture including T. cruzi IV. The SC97 isolate showed fragments of both 110 and $125 \mathrm{bp}$ and the SC90 and SC93 isolates exhibited fragments of $\sim 117$ and $125 \mathrm{bp}$, all of which are compatible with a probable mixture of $T$. cruzi I and II (Table III).

RFLP of $k D N A$ minicircle variable regions - Isolates SC96, SC97, SC98, SC99 and SC-101 were characterised by the schizodeme analysis with RsaI, EcoRI and $\operatorname{Hinf} \mathrm{I}$ endonucleases. All three endonucleases generated profiles with genetic distances indicating a high degree of genetic differentiation. The restriction with EcoRI showed that SC90 and SC93 shared 86\% similarity with one another and $70 \%$ similarity with isolates SC94, SC96 and SC97. The other three isolates (SC98, SC99 and SC101) formed a new profile with $78 \%$ similarity among themselves. The restriction with $\operatorname{Hinf} \mathrm{I}$ clustered five isolates (SC96, SC97, SC98, SC99 and SC101) with $75 \%$ similarity. Again, the marsupial and triatomine isolates grouped with $80 \%$ similarity. These strains showed greater heterogeneity when restricted with RsaI.
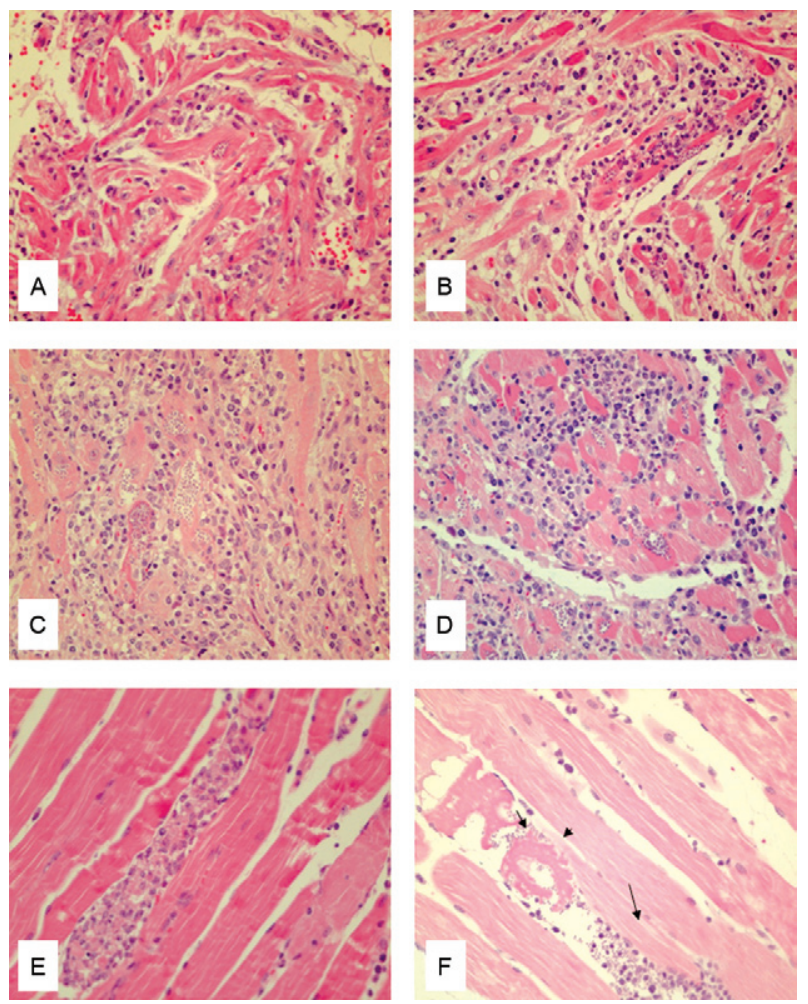

Fig. 2: histopathological aspects of the heart and skeletal muscles of mice infected with SC94 strain. A: 10th day of infection (sections of the heart showing mild interstitial inflammation and rare intracellular parasites); B: 14th day of infection [increased inflammation with presence of intracellular amastigotes and necrosis of parasitized cells, haematoxylin and eosin (H\&E) 400X]; C, D: SC100 strain, 20th day of infection (marked parasitism of cardiomyocytes, diffuse and focal infiltration by mononuclear cells replacing disintegrating myocytes, H\&E 400X); E: SC100, 14th day of infection (sections of skeletal muscle, focal destruction of myocytes with intense focal mononuclear cells infiltration, moderate interstitial inflammatory infiltration); F: SC100, 20th day of infection [parasitized skeletal myocite with focal necrosis $(\rightarrow)$ and amastigotes in desintegration $(\rightarrow)$ ]. 


\section{DISCUSSION}

The 2005 outbreak of oral T. cruzi infection that occurred in SC resulted in the infection of several people at the same locality and under the same circumstances, leading to the conclusion that all individuals were infected with the same $T$. cruzi strain. The present study was a unique opportunity to investigate the biological and biochemical behaviour of these strains after human infection and passage through an experimental animal and to correlate these characteristics of the parasite with their molecular patterns according to the New Consensus on T. cruzi Nomenclature, proposed in 2009 (Zingales et al. 2009).

In the present investigation, several methods were used for biological characterisation: parasitaemia, mortality, virulence, histopathological lesions, tissue tropism and pathogenicity in mice. Based on these parameters, all the isolated strains exhibited the patterns described for biodeme type II, as described previously (Andrade et al. 2006b). Interestingly, six of the nine human strains classified as biodeme type II presented double peaks of parasitaemia (SC96, SC97, SC98, SC99, SC101 and
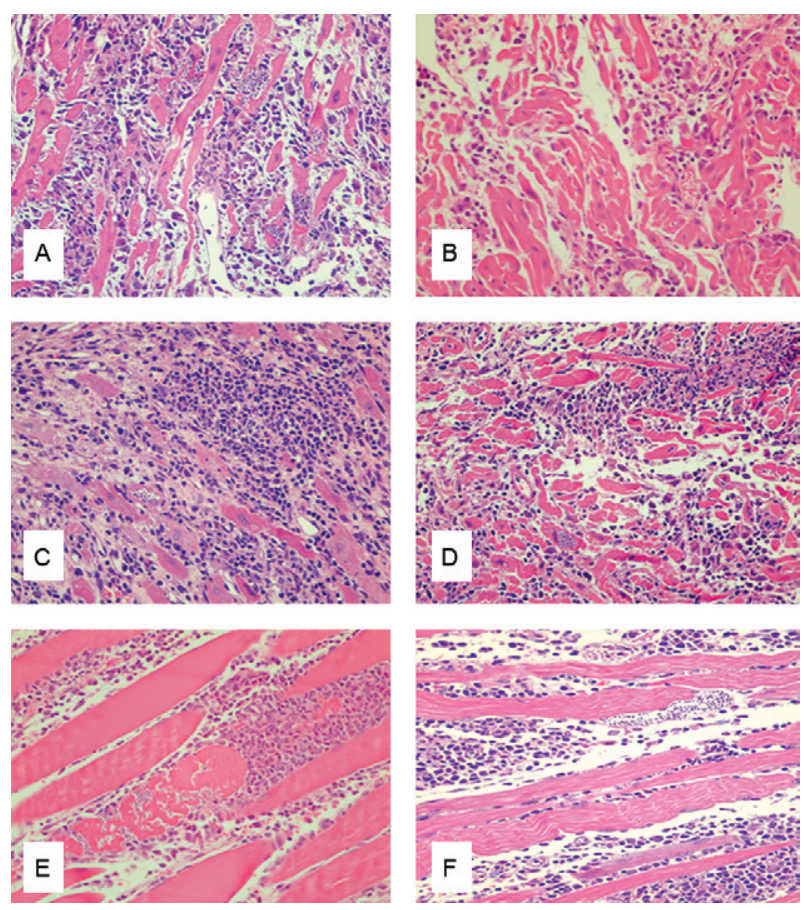

Fig. 3: histopathological lesions of the heart and skeletal muscles of mice infected with Trypanosoma cruzi strains representing a mixture of T. cruzi I and II (SC97, SC99, SC101). A: SC97 strain, 20th day of infection [cardiac myocells containing T. cruzi amastigotes are dissociated by an intense mononuclear infiltrate with focal disintegration of parasitized myocells, haematoxylin and eosin (H\&E) 400X]; B: SC 101 strain, 25th day of infection (focal areas of disintegration of cardiac myocells and mononuclear cell infiltration, H\&E 400X); C, D: SC99, 20th and 30th day of infection (increased myocardium destruction, intense mononuclear cells infiltration, presence of amastigotes within cardiac myocells, H\&E 400X); E, F: SC101 and SC99, 20th and 30th day (intense lesions of skeletal muscles, necrosis of parasitized myocells, intense diffuse and focal inflammatory infiltration, H\&E 400X).
SC102) in experimental mice, with the early low peak characteristic of this biodeme and a late peak after the 20th day that corresponds to the parasitaemia pattern of biodeme type III. These findings suggest the presence of a mixed infection. In the early phase of the infection by these strains, the histopathological patterns were characteristic of biodemes type II; however, lesions and intracellular parasitism were more prominent from the 20th to 30th days post-infection, with intense inflammatory lesions in the myocardium and skeletal muscles, which is characteristic of infection with strains belonging to biodeme type III. Additionally, the isoenzymic characterisation of the nine strains isolated from humans presented Z1 or Z2 profiles by PGM, ALAT and ASAT

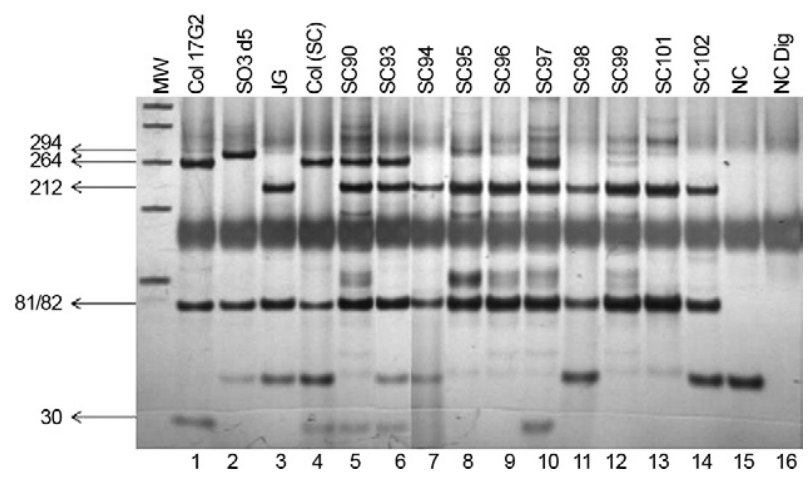

Fig. 4: polymerase chain reaction (PCR)-restriction fragment length polymorphism profiles of the cytochrome oxidase II gene after AluI digestion on silver stained 6\% polyacrylamide gel. 1-4: Trypanosoma cruzi reference strains; 5-14: T. cruzi isolates from the oral outbreak; MW: 1 kb Plus DNA Ladder (Invitrogen ${ }^{\circledR}$ ); NC: negative PCR control; NC Dig: negative AluI digestion.

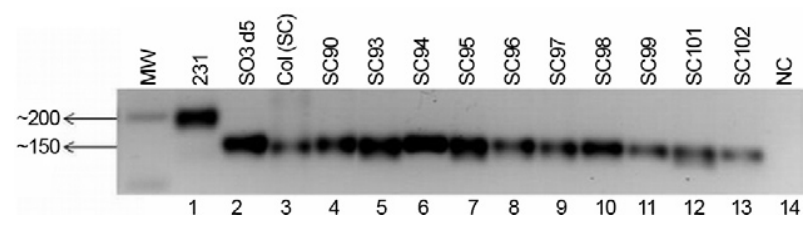

Fig. 5: spliced leader intergenic region profiles on bromide ethidium stained 2\% agarose gel. 1-3: Trypanosoma cruzi reference strains; 4-13: T. cruzi isolates from the oral outbreak; MW: $1 \mathrm{~kb}$ Plus DNA Ladder $\left(\right.$ Invitrogen $\left.{ }^{\circledR}\right)$; NC: negative polymerase chain reaction control.

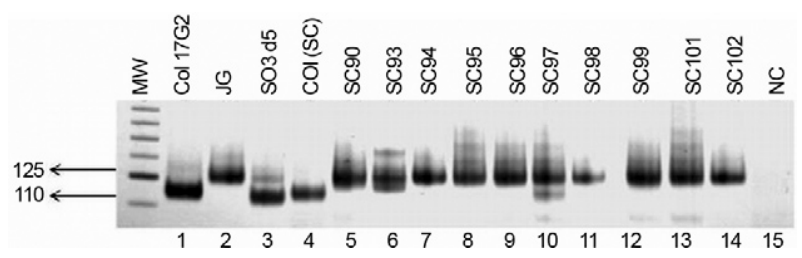

Fig. 6: $24 \mathrm{~S} \alpha$ rDNA profiles on silver stained $6 \%$ polyacrylamide gel electrophoresis. 1-4: Trypanosoma cruzi reference strains; 5-14: T. cruzi isolates; MW: 25 bp DNA Ladder $\left(\right.$ Invitrogen $^{\circledR}$ ); NC: negative polymerase chain reaction control. 
analyses and Z2 profiles by GPI analysis. The presence of a variant pattern of PGM analysis for the strains isolated from humans and a mixed $\mathrm{Zl} / \mathrm{Z} 2$ profile for the strains SC92 and SC93 isolated from T. tibiamaculata has been previously observed by Steindel et al. (2008), who demonstrated for the first time the transmission of a mixed infection by this vector in SC. According to Miles and Cibulskis (1986), some strains isolated from either single mammals or vectors may consist of heterogeneous mixtures; combinations of different isoenzymes eletrophoretic profiles could help elucidate epidemiological questions, define taxa and detect genetic exchanges. The strain SC90 (isolated from $D$. aurita), initially described as T. cruzi I (Steindel et al. 2008) by multiloci isoenzymes, was revealed in the present investigation via molecular characterisation to be a mixture of $T$. cruzi I + T. cruzi II genotypes. Steindel et al. (1995) previously reported mixed $T$. cruzi $\mathrm{I}+T$. cruzi II infections in adult Panstrogylus megistus in SC. The occurrence of mixed populations in many of the isolates of SC may explain the apparent incongruity of the zymodeme profiles observed for these populations, which present as either Z1 or Z2, depending on the isoenzyme used for analysis.

Some characteristics emerge from these studies, such as the high virulence of two strains isolated from humans (SC94 and SC99), both characterised as the T. cru$z i$ II genotype, and exhibited $100 \%$ mortality in the early

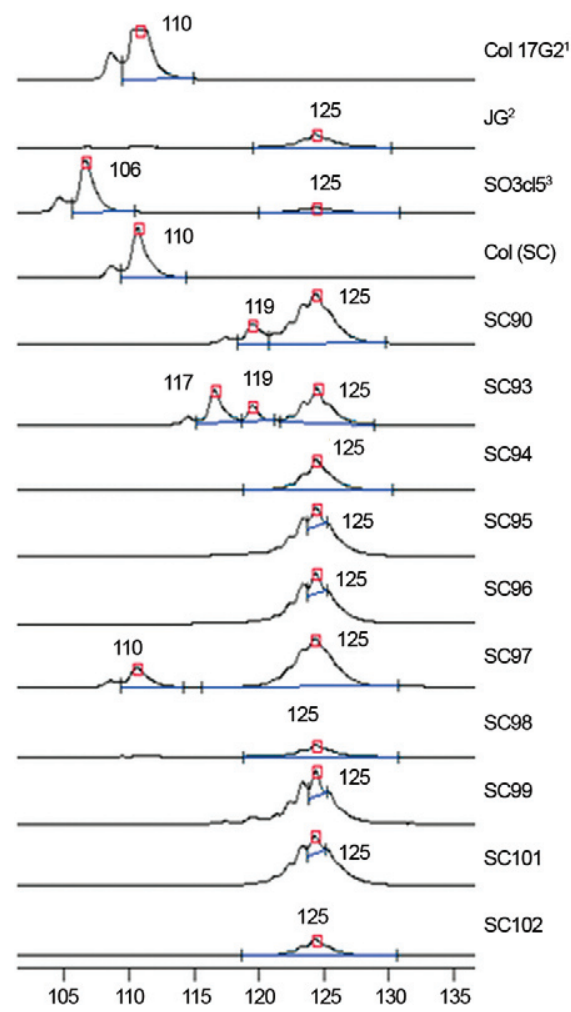

Fig. 7: automatic laser fluorescent DNA sequencer electrofluorograms presenting the Trypanosoma cruzi amplicons obtained by the analysis of $24 \mathrm{~S} \alpha \mathrm{rDNA}$ gene. Numbers at the peaks refer to the size of the amplicons in base pairs. Control patterns: ${ }^{1}$ rDNA group $1 ;{ }^{2} \mathrm{rDNA}$ group $2 ;{ }^{3}$ rDNA group $1 / 2$. phase of acute experimental infection. It was shown that the strains isolated either from the marsupial (SC90) or from the insect vector (SC93) exhibited low virulence, although they contained mixed strains (T. cruzi $\mathrm{I}+T$. cruzi II). Pena et al. (2011), utilising vector-derived mixed TcI/ TcII infective trypomastigotes (SC90-SC102), showed that $T$. cruzi II, but not $T$. cruzi I strains, were selected by both human and murine macrophages in vitro and by peritoneal cavity cells of Balb/c mice in vivo.

Molecular characterisation revealed the presence of T. cruzi II parasites in all isolates, which may reflect the fact that this is the major $T$. cruzi lineage associated with human cases in southern Brazil (Freitas et al. 2005). However, a combination of T. cruzi II with other types was observed in four samples (SC90, SC93, SC95 and SC97). To identify these mixtures and the correct major lineages, simultaneous analyses using three different molecular approaches were necessary.

The initial RFLP analysis of the COII gene revealed the presence of different combinations of the three possible haplotypes, corresponding to three cases of mixed populations of T. cruzi I + T. cruzi II (SC90, SC93, SC97) and a single case (SC95) of a mixed population T. cruzi II and either T. cruzi III, IV, V or VI. To discriminate among these possibilities, molecular typing of the SLIR was applied. Identification of mini-exon amplicons of $150 \mathrm{bp}$ characteristic of $T$. cruzi I, II, V or VI ruled out

TABLE III

Identification of phylogenetic discrete typing units (DTU) for the Trypanosoma cruzi isolates employing the cytochrome oxidase (CO)II haplotypes spliced leader intergenic region (SL-IR) and 24S $\alpha$ rDNA markers

\begin{tabular}{|c|c|c|c|c|}
\hline $\begin{array}{l}\text { T. cruzi } \\
\text { isolates }\end{array}$ & $\begin{array}{c}\text { COII } \\
\text { haplotypes }\end{array}$ & $\begin{array}{l}\text { rDNA } 24 \mathrm{~S} \alpha \\
\quad(\mathrm{bp})\end{array}$ & $\begin{array}{l}\text { SL-IR } \\
(\sim \mathrm{bp})\end{array}$ & $\begin{array}{l}\text { T. } \text { cruzi } \\
\text { DTUs }^{b}\end{array}$ \\
\hline $\mathrm{Col} 17 \mathrm{G} 2^{a}$ & A & 110 & 150 & I \\
\hline $\mathrm{JG}^{a}$ & $\mathrm{C}$ & 125 & 150 & II \\
\hline $231^{a}$ & $\mathrm{~B}$ & 110 & 200 & III \\
\hline Can III $^{a}$ & B & 125 & 200 & IV \\
\hline $\mathrm{SO} 3 \mathrm{cl}^{a}$ & $\mathrm{~B}$ & $110+125$ & 150 & $\mathrm{~V}$ \\
\hline $\mathrm{CL}$ Brener $^{a}$ & $\mathrm{~B}$ & 125 & 150 & VI \\
\hline SC90 & $A+C$ & $119+125$ & 150 & $\mathrm{I}+\mathrm{II}$ \\
\hline SC93 & $A+C$ & $117+119+125$ & 150 & $\mathrm{I}+\mathrm{II}$ \\
\hline SC94 & $\mathrm{C}$ & 125 & 150 & II \\
\hline SC95 & $\mathrm{B}+\mathrm{C}$ & 125 & 150 & $\mathrm{II}+\mathrm{VI}$ \\
\hline SC96 & $\mathrm{C}$ & 125 & 150 & I \\
\hline SC97 & $\mathrm{A}+\mathrm{C}$ & $110+125$ & 150 & $\mathrm{I}+\mathrm{II}$ \\
\hline SC98 & $\mathrm{C}$ & 125 & 150 & II \\
\hline SC99 & $\mathrm{C}$ & 125 & 150 & II \\
\hline SC101 & $\mathrm{C}$ & 125 & 150 & II \\
\hline SC102 & $\mathrm{C}$ & 125 & 150 & II \\
\hline
\end{tabular}

a: T. cruzi strains or clones used as reference to COII haplotypes, $24 \alpha$ rDNA and SL-IR marker; $b$ : according to Zingales et al. (2009). 
the possibility of SC95 existing as a mixture of T. cruzi II with $T$. cruzi III or IV. Finally, analysis of the $24 \mathrm{~S} \alpha$ rRNA gene demonstrated that SC-95 exhibited only amplicons of $125 \mathrm{bp}$, characteristic of T. cruzi II, III or VI, resulting in the conclusion that SC95 constitutes a mixture of T. cruzi II and T. cruzi VI.

The presence of mixtures of different genotypes in isolates of the SC strains from infected humans, the mammalian reservoir and the insect vector could have influenced the clinical presentation of the disease, as the lethality in the acute phase was unusually high (12.5\%). The unusually high mortality index in this outbreak contrasts with clinical surveys that have demonstrated a mortality rate varying from 5-9\% in the acute phase of infections. We cannot exclude the possibility that the inoculum and the route of infection affect the parasite burden and consequently the severity of the disease in infected individuals. However, different studies have demonstrated that the presence of mixed populations can interfere in the course and severity of experimental infections and in the host immune response (Rodrigues et al. 2010).

Experimentally, multiple infections performed by Andrade et al. (2006a) presented worsening of the infection and tissue lesions in mice successively inoculated with strains of the three different $T$. cruzi biodemes (Y, 21SF and Colombian strains). In the triple-infected mice, it was possible to re-isolate the three inoculated strains, taking into account their biological behaviour, after successive passages in young mice (Andrade et al. 2006a). In the present study, the different genotypes detected by a combination of molecular techniques in several samples isolated from human cases reflect the complexity of the tentative correlations between the parasite isolates and the clinical manifestations of Chagas disease.

Considering the different approaches in the present investigation, we conclude that oral transmission represents an important factor for the emergence of acute Chagas disease outbreaks, even for non-endemic areas. Biological, biochemical and molecular analyses detected the presence of mixed infections with different genotypes, possibly related to the different clinical courses of the acute human cases, as observed during the SC oral outbreak. Interestingly, a concordance between the biological and isoenzymic characters confirmed the presence of mixed infections, not only in the vector but also in the vertebrate reservoir and in human isolates. The heterogeneity of the isolated strains was confirmed by genotyping according to the new T. cruzi taxonomy (Zingales et al. 2009).

\section{REFERENCES}

Andrade SG 1974. Caracterização de cepas do Trypanosoma cruzi isoladas no Recôncavo Baiano. Rev Patol Trop 3: 65-121.

Andrade SG 1985. Morphological and behavioural characterization of Trypanosoma cruzi strains. Rev Soc Bras Med Trop 18 (Suppl.): 39-46.

Andrade SG, Campos RF, Sobral KSC, Magalhães JB, Guedes RSP, Guerreiro ML 2006a. Reinfections with strains of Trypanosoma cruzi of different biodemes as a factor of aggravation of myocarditis and myositis in mice. Rev Soc Bras Med Trop 39: 1-8.

Andrade SG, Magalhães JB 1997. Biodemes and zymodemes of Trypanosoma cruzi strains: correlations with clinical data and experimental pathology. Rev Soc Bras Med Trop 30: 27-35.
Andrade SG, Magalhães JB, Sobral KS, Rosado AP, Oliveira PLS 2006b. Caracterização de cepas do Trypanosoma cruzi isoladas durante surto agudo de doença de Chagas por transmissão oral em Santa Catarina, Brasil. Rev Soc Bras Med Trop 39 (Suppl. 1): 7.

Andrade V, Brodskyn C, Andrade SG 1983. Correlation between isoenzyme patterns and biological behaviour of different strains of Trypanosoma cruzi. Trans R Soc Trop Med Hyg 77: 796-799.

Anonymous 1999. Recommendations from a Satellite Meeting. Mem Inst Oswaldo Cruz 94 (Suppl. I): 429-432.

Avila H, Gonçalves AM, Neheme NS, Morel CM, Simpson L 1990. Schizodeme analysis of Trypanosoma cruzi stocks from South and Central America by analysis of PCR-amplified minicircle variable region sequences. Mol Biochem Parasitol 42: 175-188.

Brisse S, Dujardin JC, Tibayrenc M 2000. Identification of six Trypanosoma cruzi lineages by sequence-characterised amplified region markers. Mol Biochem Parasitol 111: 95-105.

Burgos JM, Atcheh J, Bisio M, Duffy T, Valadares HM, Seidenstein ME, Piccinali R, Freitas JM, Levin MJ, Macchi L, Macedo AM, Freilij H, Schijman AG 2007. Direct molecular profiling of minicircle signatures and lineages of Trypanosoma cruzi bloodstream populations causing congenital Chagas disease. Int J Parasitol 37: 1319-1327.

Freitas JM, Augusto-Pinto L, Pimenta JR, Bastos-Rodrigues L, Gonçalves VF, Teixeira SM, Chiari E, Junqueira AC, Fernandes O, Macedo AM, Machado CR, Pena SD 2006. Ancestral genomes, sex and the population structure of Trypanosoma cruzi. PLos Pathogens 2: 226-235.

Freitas JM, Lages-Silva E, Crema E, Pena SD, Macedo AM 2005. Real time PCR strategy for the identification of major lineages of Trypanosoma cruzi directly in chronically infected human tissues. Int J Parasitol 35: 411-417.

Miles MA, Cibulskis RE 1986. Zymodeme characterization of Trypanosoma cruzi. Parasitology Today 2: 94-101.

Miles MA, Laham SM, Souza AA, Povoa M 1980. Further enzymic characters of Trypanosoma cruzi and their evaluation for strain identification. Trans R Soc Trop Med Hyg 74: 221-237.

Nery-Guimarães F, Silva NN, Clausell DT, de Mello AL, Rapone T, Rodrigues N 1968. Um surto epidêmico de doença de Chagas de provável transmissão digestiva ocorrida em Teutônia (EstrelaRio Grande do Sul). Hospital (RJ) 73: 1767-1804.

Neves da Silva N, Clausell DT, Nólibos H, de Mello AL, Ossanai J, Rapone T, Snell T 1968. Surto epidêmico de doença de Chagas com provável contaminação oral. Rev Inst Med Trop Sao Paulo 10: $265-276$.

Pena DA, Eger I, Nogueira L, Heck N, Menin A, Bafica A, Steindel M 2011. Selection of TcII Trypanosoma cruzi population following macrophage infection. J Infect Dis 204: 478-486.

Pinto AY, Harada GS, Valente VC, Araújo JE, Gomes FS, Souza GC, Valente SA 2001. Acometimento cardíaco em pacientes com doença de Chagas aguda em microepidemia familiar, em Abaetetuba, na Amazônia Brasileira. Rev Soc Bras Med Trop 34: 413-419.

Rodrigues CM, Valadares HMS, Francisco AF, Arantes JM, Campos CF, Carvalho AT, Filho OAM, Araújo MSS, Arantes RME, Chiari E, Franco GR, Machado CR, Pena SDJ, Faria AMC, Macedo AM 2010. Coinfection with different Trypanosoma cruzi strains interferes with the host immune response to infection. PLoS Negl Trop Dis 4: e846.

Shikanai-Yasuda MA, Marcondes CB, Guedes LA, Siqueira GS, Barone AA, Dias JCP, Amato Neto V, Tolezano JE, Peres BA, Arruda Jr. ER, Lopes MH, Shiroma M, Chapadeiro E 1991. Possible oral transmission of acute Chagas' disease in Brazil. Rev Inst Med Trop Sao Paulo 33: 351-357. 
Souto RP, Fernandes O, Macedo AM, Campbell DA, Zingales B 1996. DNA markers define two major phylogenetic lineages of Trypanosoma cruzi. Mol Biochem Parasitol 83: 141-152.

Steindel M, Pacheco LK, Scholl D, Soares M, Moraes MH, Eger I, Kosmann C, Sincero TCM, Stoco PH, Murta SMF, Carvalho-Pinto CJ, Grisard EC 2008. Characterization of Trypanosoma cruzi isolated from humans, vectors and animal reservoirs following an outbreak of acute human Chagas disease in Santa Catarina state, Brazil. Diag Microbiol Infect Dis 60: 25-32.

Steindel M, Toma HK, Ishida MM, Murta SM, Carvalho Pinto CJ, Grisard EC, Schlemper Jr. BR, Ribeiro-Rodrigues R, Romanha AJ 1995. Biological and isoenzymatic characterization of Trypanosoma cruzi strains isolated from sylvatic reservoirs and vectors from the state of Santa Catarina, southern Brazil. Acta Trop 60: 167-177.

Tibayrenc M 1998. Genetic epidemiology of parasitic protozoa and other infectious agents: the need for an integrated approach. Int Parasitol 28: 85-104.
Tibayrenc M 2003. Genetic subdivisions within Trypanosoma cruzi (discrete typing units) and their relevance for molecular epidemiology and experimental evolution. Kinetoplastid Biology and Disease 2: 12.

Valente SA, Valente VC, Fraiha Neto H 1999. Considerações sobre a epidemiologia e transmissão da doença de Chagas na Amazônia Brasileira. Rev Soc Bras Med Trop 32 (Suppl. 2): 51-55.

Valente SAS, Valente VC, Pinto AYN, César MJB, Santos MP, Miranda CO, Cuervo P, Fernandes O 2009. Analysis of an acute Chagas disease outbreak in the Brazilian Amazon: human cases, triatomines, reservoir mammals and parasites. Trans $R$ Soc Trop Med Hyg 103: 291-297.

Zingales B, Andrade SG, Briones MRS, Campbell DA, Chiari E, Fernandes O, Guhl F, Lages-Silva E, Macedo AM, Machado CR, Miles MA, Romanha AJ, Sturm NR, Tybayrenc M, Schijman AG 2009. A new consensus for Trypanosoma cruzi intraspecific nomenclature: second revision meeting recommends Tcl to TcVI. Mem Inst Oswaldo Cruz 104: 1051-1054. 